\title{
Inflammation Markers in Healthy and Periodontitis Patients. A Preliminary Data Screening
}

\author{
Adriana Corrêa de QUEIROZ \\ Mario TABA Jr. \\ Patrícia Aquino O’CONNELL \\ Priscila Brasil da NÓBREGA \\ Priscila Paganini COSTA \\ Viviane Keiko dos Santos KAWATA \\ Glauce Lunardelli TREVISAN \\ Arthur Belém NOVAES Jr. \\ Sergio Luís Scombatti de SOUZA \\ Daniela Bazan PALIOTO \\ Márcio Fernando de Moraes GRISI
}

Department of Oral and Maxillofacial Surgery and Traumatology and Periodontics, School of Dentistry of Ribeirão Preto, University of São Paulo, Ribeirão Preto, SP, Brazil

\begin{abstract}
Advances in diagnostic research are moving towards methods whereby the periodontal risk can be identified and quantified by objective measures using biomarkers. Patients with periodontitis may have elevated circulating levels of specific inflammatory markers that can be correlated to the severity of the disease. The purpose of this study was to evaluate whether differences in the serum levels of inflammatory biomarkers are differentially expressed in healthy and periodontitis patients. Twenty-five patients ( 8 healthy patients and 17 chronic periodontitis patients) were enrolled in the study. A $15 \mathrm{~mL}$ blood sample was used for identification of the inflammatory markers, with a human inflammatory flow cytometry multiplex assay. Among 24 assessed cytokines, only 3 (RANTES, MIG and Eotaxin) were statistically different between groups $(\mathrm{p}<0.05)$. In conclusion, some of the selected markers of inflammation are differentially expressed in healthy and periodontitis patients. Cytokine profile analysis may be further explored to distinguish the periodontitis patients from the ones free of disease and also to be used as a measure of risk. The present data, however, are limited and larger sample size studies are required to validate the findings of the specific biomarkers.
\end{abstract}

Key Words: serum, biomarkers, periodontitis.

\section{INTRODUCTION}

Periodontitis is a group of inflammatory diseases that affect the connective tissue attachment and supporting bone around the teeth. It results from interactions between periodontal microflora and the multifaceted response of the host. Initiation and progression of periodontitis are dependent on the presence of virulent microorganisms capable of causing disease. Although bacteria are initiating agents in periodontitis, host re- sponse to the pathogenic infection is critical to disease progression (1).

Over the last 50 years, the prevailing view among dentists and physicians has been that periodontal infections are localized only to the marginal periodontium and that, as such, they rarely have systemic implications in healthy individuals. More recent evidence, however, has indicated that periodontitis patients present increased systemic inflammation, as indicated by elevated serum levels of various inflammatory markers when compared

Correspondence: Prof. Dr. Mário Taba Jr., Departamento de Cirurgia e Traumatologia Buco-Maxilo-Facial e Periodontia, Faculdade de Odontologia de Ribeirão Preto, USP, Avenida do Café, S/N, 14040-904 Ribeirão Preto, SP, Brasil. Tel: +55-16-3602-3980. Fax: +55-163602-4788. e-mail: mtaba@forp.usp.br 
to those in unaffected control populations (2).

The diagnosis of active phases of periodontal disease and the identification of patients at risk for active disease represent a challenge for both clinical investigators and clinicians. Advances in oral and periodontal disease diagnostic research are moving towards methods whereby periodontal risk can be identified and quantified by objective measures, such as biomarkers. These biomarkers of host response can be found in gingival crevicular fluid, saliva and serum samples and can potentially be used as diagnostic markers (3).

It has been proposed that patients with periodontitis may have elevated circulating levels of some inflammatory markers. Monocytes, macrophages and other cells (including fibroblasts and endothelial cells) respond to the dental plaque microorganisms, membraneassociated vesicles, lipopolysaccharides (LPS), and other soluble and particular fractions by secreting a number of chemokines and inflammatory cytokines, especially tumor necrosis factor (TNF)- $\alpha$, prostaglandin $\left(\mathrm{PGE}_{2}\right)$, interleukins (IL-1 $\beta$ and IL-6). These inflammatory cytokines and prostaglandin have been associated with the presence of various bacterial infections including periodontitis (4).

Elevated levels of IL- 6 in blood or biological fluids have been reported in association with immunopathologies, such as in tissue injury, infection and some inflammatory diseases (5). Many studies have shown dramatic elevation of IL-6 levels in inflammatory periodontal lesions and IL-6 is also thought to be a useful indicator or a diagnostic marker for periodontitis (6-8). The elevation in cytokines expression by cells within the gingival connective tissue in chronic periodontitis lesions can theoretically spill over into the circulation where it can induce or perpetuate systemic effects (9).

Although several studies $(7,8,13-15)$ has demonstrated that the biological activity of a variety of cytokines may be directly relevant to periodontal destruction, such as periodontal attachment loss, destruction of collagen and alveolar bone resorption. Biologic mechanisms for the progression of periodontitis are not fully understood and, though much attention has been focused on this subject, still remain controversial. The individual course of periodontal diseases and the variability of clinical parameters, which may lead to tooth loss in the absence of early and appropriate treatment, led us to undertake a complex study on the key cytokines responsible for the initiation, progression and/or sup- pression of inflammatory response (10). Thus, considering the evidences and need to further investigate the advances in oral and periodontal disease diagnostic research, the purpose of this study was to evaluate the differences in the serum levels of inflammatory biomarkers in healthy and periodontitis patients.

\section{MATERIAL AND METHODS}

\section{Study Population}

This clinical study was conducted as a joint collaboration of the Department of Oral and Maxillofacial Surgery and Traumatology and Periodontics, School of Dentistry of Ribeirão Preto, and the Department of Clinical Analysis, School of Pharmaceutics Sciences of Ribeirão Preto, University of São Paulo.

Patients that fulfilled the entry clinical criteria for the inclusion in the study were examined by a single experienced examiner and, according to their periodontal condition and general health status, they were either invited or not to participate in the study.

Inclusion criteria were: (i) healthy patients; (ii) at least one site with probing depth $\geq 5 \mathrm{~mm}$ and two teeth with attachment loss $\geq 6 \mathrm{~mm}$ (11). Exclusion criteria were: (i) use of antibiotics or periodontal treatment in the previous 6 months; (ii) smoking within the past 5 years; (iii) pregnancy or lactancy; (iv) concomitant medical therapy. The study was independently reviewed and approved by the Institutional Human Research Committee. The patients who qualified for the study were rescheduled for laboratory, periodontal, radiographic and clinical examinations. From the initial screening, 25 patients $(8$ healthy individuals +17 chronic periodontitis patients) met all inclusion criteria, did not meet any exclusion criteria, and agreed to participate in the study.

\section{Clinical Data Collection}

The periodontal measurements were performed by a single experienced examiner and recorded at 6 sites per tooth using a computerized periodontal probe (Florida Probe ${ }^{\circledR}$; Florida Probe Corporation, Gainesville, FL, USA). The parameters recorded were as follows: probing pocket depth (PPD), clinical attachment level (CAL), bleeding on probing (BOP), number of teeth (N. teeth), probing pocket depth $\geq 7 \mathrm{~mm}$ (PPD $\geq 7 \mathrm{~mm}$ ) and probing pocket depth between $4 \mathrm{~mm}$ and $6 \mathrm{~mm}$ (PPD 4-6 mm). 


\section{Inflammatory Markers and Sample Collection}

A $15 \mathrm{~mL}$ blood sample was obtained by venipuncture from each participant. Serum was collected by centrifugation, aliquoted, stored and processed at the end of the study by blinded staff.

The inflammatory markers were simultaneously identified using human inflammatory flow cytometry multiplex assays (BD ${ }^{\text {TM }}$ Cytometric Bead Array - CBA; BD Bioscience, San Jose, CA, USA). CBA, commonly referred to as a multiplexed bead assay, is a series of spectrally discrete particles that can be used to capture soluble analytes. The analytes are then measured by detection of a fluorescence-based emission and flow cytometric analysis. The method employs a series of different particles that are stably labeled with a fluorescent dye whose emission wavelength is read at $\sim 650$ $\mathrm{nm}$. Each different group of beads is labeled with a discrete level of fluorescent dye so that it can be distinguished by its mean fluorescent intensity. The beads within each group are covalently coupled with antibodies that can specifically capture a particular type of molecule present within biological fluids.

The multiplex assay was chosen because it allows a more complete analysis of biomarkers involved in periodontitis and systemic diseases.

\section{Statistical Analysis}

Mean CAL, PPD, BOP, N. teeth and serum biomarkers were calculated for each subject and group, and were compared between the two groups using a two-sample Mann-Whitney U test. Data were tested for normality before applying the adequate non-parametric tests. Correlation between serum biomarkers and clinical parameters was verified by computing Pearson's Correlation Coefficient. Statistical significance was considered for $\mathrm{p}$-value $<0.05$.

\section{RESULTS}

\section{Clinical Parameters}

The periodontal measurements and levels of inflammatory mediators were measured in serum samples of 17 patients with chronic periodontitis (test group), as well as 8 healthy subjects (control group).

The periodontal measurements of participants recruited for this study are summarized in Table 1. For the Mann-Whitney test, data showed that the periodontal parameters evaluated (PPD, PPD 4-6 mm, PPD $\geq 7$ $\mathrm{mm}, \mathrm{CAL}, \mathrm{BOP}$ and $\mathrm{N}$. teeth), when compared between groups (control and test) was statistically significant ( $p$ $\leq 0.001)$. The control group showed no signs of inflammation (e.g.: BOP) or periodontal pockets, whereas in test group, inflammation and periodontal pockets were always present. In addition, the test group showed periodontitis regarding its type (chronic periodontitis) and severity (moderate to severe probing depth $\geq 6 \mathrm{~mm}$ ). However, in most subjects, moderate to severe periodontitis was localized on some teeth.

\section{Immunological Parameters}

Table 2 shows the levels of serum mediators in both groups. Theinflammatory mediators IL-9, RANTES, Human GM-CSF, MIP- $1 \beta$ and INF- $\gamma$ were reduced in test patients compared to control patients, but only RANTES levels were statistically significant $(\mathrm{p}=0.016)$. IL-1 $\beta$, MIG, IL-2, IL-4, IL-5, IL-6, IL-7, IL-8, IL-10, IL12p70, IP-10, Human B FGF, Human Fas Ligand, Human G-CSF, Human LT- $\alpha$, Human MCP-1, MIP-1 $\alpha$, Human TGF- $\beta$, G-CSF, Eotaxin and TNF- $\alpha$ levels were increased when test and control groups were compared, but only MIG and Eotaxin levels were statistically significantly ( $\mathrm{p}=0.033$ and $\mathrm{p}=0.0124$ respectively).

\section{Levels of Serum Mediators Correlated with Clinical Parameters}

The correlation between serum mediators and clinical parameters was analyzed for Eotaxin, RANTES

Table 1. Periodontal measurements of patients.

\begin{tabular}{lcrc}
\hline Clinical parameters & Control group & Test group & $p$ value \\
\hline PPD & $1.75 \pm 0.27$ & $3.22 \pm 1.08$ & $\mathrm{p}<0.001$ \\
PPD 4-6 mm & 0.00 & $13.71 \pm 9.05$ & $\mathrm{p}<0.001$ \\
PPD $\geq 7 \mathrm{~mm}$ & 0.00 & $4.53 \pm 5.36$ & $\mathrm{p}=0.001$ \\
CAL & $1.73 \pm 0.29$ & $3.76 \pm 1.11$ & $\mathrm{p}<0.001$ \\
BOP & 0.00 & $0.48 \pm 0.24$ & $\mathrm{p}<0.001$ \\
N. teeth & $29.71 \pm 2.14$ & $21.72 \pm 4.44$ & $\mathrm{p}<0.001$
\end{tabular}

$\mathrm{PPD}=$ probing pocket depth $\mathrm{CAL}=$ clinical attachment level; $\mathrm{BOP}=$ bleeding on probing; $\mathrm{N}$. teeth $=$ number of teeth. 
and MIG, which showed statistical significance. RANTES showed higher levels in the control group than in the test group, though when correlated with all clinical parameters, it presented lower levels of correlation without statistical significance (Table 3). In the test group, there were higher levels of Eotaxin and MIG. Eotaxin did not show statistically significant correlation with any clinical parameter. Elevated MIG levels were correlated only with N. teeth. However, in this case, the correlation was not statistically significant (Table 4).

\section{DISCUSSION}

Cytokines are small polypeptides with a wide spectrum of inflammatory, hemopoietic, metabolic and immunomodulatory properties. They are produced by a variety of cells, including the macrophage/monocyte

Table 2. Serum mediators ( $\mathrm{pg} / \mathrm{mL}$ ) of control and test groups.

\begin{tabular}{lcccc}
\hline Mediator & Control group & Test group & $p$ value & \\
\hline IL-2 & $7.8 \pm 15.1$ & $13.0 \pm 25.2$ & 0.2953 & $\uparrow$ \\
IL-4 & $2.1 \pm 3.5$ & $4.7 \pm 9.4$ & 0.2375 & $\uparrow$ \\
IL-5 & $2.3 \pm 0.7$ & $2.5 \pm 4.7$ & 0.4460 & $\uparrow$ \\
IL-6 & $0.8 \pm 0.9$ & $2.0 \pm 3.4$ & 0.1755 & $\uparrow$ \\
IL-7 & $3.0 \pm 3.7$ & $6.0 \pm 14.6$ & 0.2879 & $\uparrow$ \\
IL-8 & $7.0 \pm 3.1$ & $10.0 \pm 12.7$ & 0.2541 & $\uparrow$ \\
IL-1 $\beta$ & $0.4 \pm 1.1$ & $5.9 \pm 15.2$ & 0.1586 & $\uparrow$ \\
IP-10 & $65.7 \pm 49.8$ & $81.1 \pm 43.7$ & 0.2199 & $\uparrow$ \\
IL-9 & $22.9 \pm 64.9$ & $1.0 \pm 3.1$ & 0.0837 & $\downarrow$ \\
IL-10 & $0.6 \pm 0.8$ & $3.0 \pm 8.5$ & 0.2132 & $\uparrow$ \\
MIP-1 $\alpha$ & $4.7 \pm 4.1$ & $10.5 \pm 17.5$ & 0.1838 & $\uparrow$ \\
Human B FGF & $14.1 \pm 39.9$ & $34.8 \pm 128.2$ & 0.3313 & $\uparrow$ \\
HumanFas Ligand & $22.3 \pm 11.1$ & $24.7 \pm 35.2$ & 0.4273 & $\uparrow$ \\
Eotaxin & $35.8 \pm 16.5$ & $74.8 \pm 44.2$ & $0.0124 *$ & $\uparrow$ \\
Human G-CSF & $6.2 \pm 4.0$ & $11.7 \pm 15.8$ & 0.1734 & $\uparrow$ \\
Human GM-CSF & $1.3 \pm 2.3$ & $0.7 \pm 2.3$ & 0.2668 & $\downarrow$ \\
RANTES & $20958.5 \pm$ & $18356.9 \pm$ & $0.0075 *$ & $\downarrow$ \\
& 2201.2 & 2356.0 & & \\
Human LT- $\alpha$ & $0.4 \pm 1.1$ & $5.3 \pm 13.9$ & 0.1652 & $\uparrow$ \\
Human MCP-1 & $77.1 \pm 44.7$ & $126.9 \pm 124.0$ & 0.1429 & $\uparrow$ \\
Human TNF & $0.9 \pm 1.8$ & $6.4 \pm 17.3$ & 0.1949 & $\uparrow$ \\
MIP-1 $\beta$ & $942.9 \pm$ & $174.2 \pm$ & 0.1037 & $\downarrow$ \\
& 2482.5 & 226.5 & & \\
IL-12 p70 & $2.9 \pm 1.7$ & $8.7 \pm 23.7$ & 0.2479 & $\uparrow$ \\
INF- $\gamma$ & $28.0 \pm 68.4$ & $17.0 \pm 28.0$ & 0.2849 & $\downarrow$ \\
MIG & $86.8 \pm 34.0$ & $194.1 \pm 186.1$ & $0.033651^{*}$ & $\uparrow$ \\
\hline & & & &
\end{tabular}

$*$ = significant difference $(\mathrm{p}<0.05)$; Values are shown as mean \pm SD. system, dendritic cells, lymphocytes, neutrophils, endothelial cells and fibroblasts. As a consequence, cytokines and their receptors form a network of high complexity that is under tight but complex biological control, including positive and negative feedback by the cytokines themselves. It is well known that immunity depends on two major types of specific immune responses, the cellular and humoral responses. The balance between them is strongly regulated by factors associated with antigen-presenting cells (APC) and by cytokines produced by $\mathrm{T}$ helper (Th) cells (12).

Several studies $(7,8,13-15)$ have demonstrated that some cytokines, such as interleukin-12 (IL-12), interleukin-1 beta (IL-1 $\beta$ ), interferon gama (IFN- $\gamma$ ), interleukin-6 (IL-6) and tumor necrosis factor alpha

Table 3. Correlations between clinical parameters and levels of serum mediators in the control patients.

\begin{tabular}{lcc}
\hline \multirow{2}{*}{$\begin{array}{l}\text { Clinical } \\
\text { Parameters }\end{array}$} & \multicolumn{2}{c}{ RANTES } \\
\cline { 2 - 3 } & Correlation & $p$ value \\
\hline CAL & 0.130 & 0.759 \\
PPD & 0.176 & 0.678 \\
PPD 4-6 mm & Not tested* & - \\
PPD $\geq 7 \mathrm{~mm}$ & Not tested* & - \\
BOP & Not tested* & - \\
N. teeth & 0.146 & 0.730 \\
\hline
\end{tabular}

*Variables not tested due to absence of clinical measurements. $\mathrm{PPD}=$ probing pocket depth; $\mathrm{CAL}=$ clinical attachment level; $\mathrm{BOP}=$ bleeding on probing; $\mathrm{N}$. teeth $=$ number of teeth.

Table 4. Correlations between clinical parameters and levels of serum mediators in the test group.

\begin{tabular}{lccccc}
\hline \multirow{2}{*}{$\begin{array}{l}\text { Clinical } \\
\text { Parameters }\end{array}$} & \multicolumn{2}{c}{ Eotaxin } & & \multicolumn{2}{c}{ MIG } \\
\cline { 2 - 3 } \cline { 5 - 6 } & Correlation & $p$ value & & Correlation & $p$ value \\
\hline CAL & 0.014 & 0.957 & & -0.25 & 0.925 \\
PPD & 0.037 & 0.887 & & -0.177 & 0.496 \\
PPD 4-6 mm & 0.015 & 0.954 & & 0.038 & 0.885 \\
PPD $\geq 7 \mathrm{~mm}$ & 0.284 & 0.269 & & -0.096 & 0.713 \\
BOP & 0.246 & 0.341 & & -0.123 & 0.638 \\
N. teeth & 0.139 & 0.596 & & 0.596 & 0.596 \\
& & & & &
\end{tabular}

$\mathrm{PPD}=$ probing pocket depth; $\mathrm{CAL}=$ clinical attachment level; $\mathrm{BOP}=$ bleeding on probing; $\mathrm{N}$. teeth $=$ number of teeth . 
(TNF- $\alpha$ ), are involved in Th1 immune responses and induce mainly cell-mediated immunity. In contrast, interleukin-4 (IL-4), interleukin-5 (IL-5) and interleukin10 (IL-10) are involved in Th2 immune responses and promote humoral immunity due to the production of B cell growth and differentiation factors (13). Cytokines produced by Th1 and Th2 cells are mutually inhibitory for the differentiation and effector functions of the reciprocal phenotype. Thus, IFN- $\gamma$ selectively inhibits the proliferation of Th2 cells, while IL-4 and IL-10 inhibit cytokine synthesis by Th1 cells. Moreover, IL4 suppresses the synthesis of proinflammatory cytokines, including IL-1 and TNF- $\alpha$, which induce several events associated with inflammation, tissue destruction, bone resorption and production of matrix metalloproteinases and prostaglandin E2 (14). One of the major sources of IL-1 $\beta$ and TNF- $\alpha$ in inflamed tissues are tissue monocytes/macrophages. IFN- $\gamma$ and IL- 2 are produced mainly by Th 1 cells, while IL- 4 and IL- 10 by the Th 2 subset. All these cytokines play a key role in immune and inflammatory responses, and infection outcome may be attributable to the balance in the relative rate among all of them.

Górska et al. (15) assessed the relationship between clinical parameters and concentrations of the key cytokines (IL-1 $\beta$, TNF- $\alpha$, IL-2, IFN- $\gamma$, IL-4, IL-10), important in the initiation and progression of periodontal disease, within inflamed gingival tissues and serum samples from patients with severe chronic periodontitis. The concentrations of IL- $1 \beta$, TNF- $\alpha$, IL- 2, IFN- $\gamma$ were, on average, significantly higher in serum samples and gingival tissue biopsies from periodontitis patients than in healthy controls. However, serum samples from both groups showed high individual variability of cytokine profiles, and no association between cytokine concentrations and clinical parameters of periodontitis was found. On the contrary, IL-4 and IL-10 levels in both kinds of samples obtained from patients and controls were generally low or even undetectable, and remained, on average, on the same level. These results indicate that high variability of cytokine concentrations and low frequency of their detection in serum samples from periodontitis patients make these determinations useless for the detection of disease presence and/or its severity.

RANTES (regulated upon activation, normal T cell expressed and secreted) is a CC chemokine, which preferentially has chemoattractant properties for monocytes and memory T cells (16). It is a pro-inflammatory chemokine and is found in sites of seveal inflammatory disorders. It is also intimately linked to the function of cytotoxic $\mathrm{T}$ lymphocytes, which are important in the control of a number of intracellular pathogens. It has been reported that chemokines, including RANTES, mediate and stimulate the release of inflammatory products. However, the relative contribution of these chemokine to the inflammatory diseases is still uncertain (17). In this study, RANTES expressed higher serum levels in the control group than in the test group. The patients answered to a strict questionnaire. However, a systemic inflammatory process could have been hidden and, as RANTES is a multipotent mediator of inflammation, the data could have been altered.

MIG (monokine induced by interferon- $\gamma$ ), a member of CXC chemokine superfamily, is up-regulated by RANKL in osteoclast precursor cells. This secreted low molecular weight protein has been implicated in the directed migration, adhesion and activation of macrophages, $\mathrm{T}$ cells, and $\mathrm{B}$ cells that express CXCR3, the receptor for MIG. Furthermore, the expression of MIG induced by RANKL can stimulate the adhesion and migration of M-CSF-dependent osteoclast precursors and differentiating osteoclasts (18). In the present study, it was observed that MIG presented higher levels in the test group, which showed worse clinical parameters (PPD, CAL). This result is accordance with the literature, since the bone resorption is an important event of destructive periodontal disease.

Eotaxin is a member of CC-chemokine family with preferential chemotactic capacity for eosinophils. Increased levels of eotaxin have been detected in the serum/plasma of subjects with asthma and allergic rhinitis, suggesting an important role in allergic diseases (19). In the present study, higher levels of Eotaxin were observed in test group. However, the literature does not show a relationship between periodontal disease and Eotaxin. Unlike other chemokines, Eotaxin binds to only one receptor, CCR3, which is highly expressed on eosinophils. It has no activity on neutrophils and monocytes, which do not seem to express CCR3. However, it does show certain degree of chemotactic activity towards Th2 cells and basophils. These cells have also been shown to express CCR3. This may explain why eotaxin has the potential to mediate the migration of these cells and their relationship with inflammatory process (20).

In conclusion, the systemic levels of the inflammatory mediators analyzed in this study presented a similar profile in healthy and periodontitis patients. 
Although some cytokines have shown significant differences between the groups, there are no compelling data at this point to indicate that they can be used as biomarkers for periodontal disease. Cytokine profile analysis should be further explored to distinguish the patients with periodontitis from those free of disease, and also to be used as a measure of risk.

\section{RESUMO}

Avanços no diagnóstico da doença periodontal levam a métodos nos quais o risco e atividade da doença periodontal podem ser identificados e quantificados por biomarcadores. Pacientes com periodontite podem apresentar elevados níveis circulatórios de marcadores inflamatórios específicos que podem ser correlacionados com a severidade da doença. Portanto, o objetivo desse estudo foi avaliar as diferenças nos níveis séricos de biomarcadores inflamatórios em pacientes saudáveis e com doença periodontal. Foram incluídos no estudo 25 pacientes ( 8 saudáveis e 17 com periodontite crônica). Uma amostra de $15 \mathrm{~mL}$ de sangue foi obtida para identificar os marcadores inflamatórios simultaneamente utilizando Array de proteínas através de citometria de fluxo. De 24 citocinas inflamatórias analisadas, apenas 3 (RANTES, MIG e Eotaxina) apresentaram diferenças estatisticamente significantes $(\mathrm{p}<0,05)$ entre os dois grupos. Conclui-se que alguns marcadores inflamatórios selecionados apresentam diferença de concentração em pacientes com periodontite e saudáveis. A análise do perfil de citocinas pode ser utilizada tanto para distinguir pacientes periodontais de pacientes saudáveis, como para medir o risco à doença. Contudo, mais estudos com número maior de amostras são necessários para validar os achados sobre os biomarcadores específicos.

\section{ACKNOWLEDGEMENTS}

The study was supported by FAPESP (grant 04/09844-8 MTJ) and CNPq (grant 470638/2006 ABNJ \& MTJ). Authors thank the kind assistance of Prof. Auro Nomizo, Analuiza S. Costa, Antônio Zanardo Filho and Fabiana R. de Morais from the Immunology Laboratory of FCFRP/USP. The SDC (sequence-determinescredit) approach was applied for the sequence of authors.

\section{NOTE FROM THE EDITORS}

This study was rewarded at the 29th JORP/2007 (Annual Scientific Meeting of the School of Dentistry of Ribeirão Preto, University of São Paulo) with publication in the Brazilian Dental Journal.

\section{REFERENCES}

1. Craig RG, Yip JK, Mijares DQ, LeGeros RZ, Socransky SS, Haffajee AD. Progression of destructive periodontal diseases in three urban minority population: role of clinical and demographic factors. J Clin Periodontol 2003;30:1075-1083.

2. Noack B, Genco RJ, Trevisan M, Grossi S, Zambon JJ, De Nardin E. Periodontal infections contribute to elevated systemic C-reactive protein level. J Periodontol 2001;72:1221-1227.

3. Ebersole JL, Machen RL, Steffen MJ, Willmann DE. Systemic acutephase reactants, C-reactive protein and haptoglobin, in adult periodontitis. Clin Exp Immunol 1997;107:347-352.

4. Beck JD, Offenbacher S, Williams R, Gibbs P, Garcia R. Periodontitis: a risk factor for coronary heart disease? Ann Periodontol 1998;3:127-141.

5. Naka T, Nishimoto N, Kishimoto T. The paradigm of IL-6: from basic science to medicine. Arthritis Res 2002;4:233-242.

6. Takahashi K, Takashiba S, Nagai A, Takigawa M, Myoukai F, Kurihara $\mathrm{H}$, et al. Assessment of interleukin 6 in the pathogenesis of periodontal disease. J Periodontol 1994;65:147-153.

7. McGee JM, Tucci MA, Edmundson TP, Serio CL, Johnson RB. The relationship between concentrations of proinflammatory cytokines within gingiva and the adjacent sulcular depth. J Periodontol 1998;69:865-871.

8. Mogi M, Otogoto J, Ota N, Inagaki H, Minami M, Kojima K. Interleukin $1 \mathrm{~b}$, interleukin 6 , b2-microglobulin, and transforming growth factor-a in gingival crevicular fluid from human periodontal disease. Arch Oral Biol 1999;44:535-539.

9. Graves DT, Liu R, Alikhani M, Al-Mashat H, Trackman PC. Diabetes-enhanced inflammation and apoptosis - impact on periodontal pathology. J Dent Res 2006;85:15-21.

10. Ishihara $Y$, Nishirara $T$, Kuroyanagi $T$, Shirozu $N$, Yamagishi E, Oliguchi M, et al.. Gingival crevicular interleukin-1 and interleukin-1 receptor antagonist levels in periodontally healthy and diseased sites. J Periodontal Res 1997;32:524-529.

11. Machtei EE, Christersson LA, Grossi SG, Dunford R, Zambon JJ, Genco RJ. Clinical criteria for the definition of "established periodontitis". J Periodontol 1992;63:206-214.

12. Mosmann TR, Sad S. The expanding universe of T-cell subsets: Th1, Th2 and more. Immunol Today 1996;17:138-148.

13. Belardelli F, Ferrantini M. Cytokines as a link between innate and adaptive antitumor immunity. T Immunol 2002;23:201-208.

14. Yucel-Lindberg T, Nilsson S, Modeer T. Signal transduction pathways in-volved in the synergistic stimulation of prostaglandin production by interleukin- $1 \mathrm{~b}$ and tumor necrosis factor a in human gingival fibroblast. J Dental Res 1999;78:61-68.

15. Górska R, Gregorek H, Kowalski J, Laskus-Perendyk A, Syczewska M, Madalinski K. Relationship between clinical parameters and cytokine profiles in inflamed gingival tissue and serum samples from patients with chronic periodontitis. J Clin Periodontol 2003;30:1046-1052.

16. Appay V, Dunbar PR, Cerundolo V, McMichel A, Czaplewski L, Rowland-Jones S. RANTES activates antigen-specific cytotoxic $\mathrm{T}$ lymphocytes in a mitogen-like manner trough cell surface aggregation. Int Immunol 2000;12:1173-1182.

17. Castellani ML, Madhappan B, Salini V, Vecchiet J, Tete S, Frydas S et al.. Rantes (CCL5) potentiates calcium ionophore in the production of LTB4 in rat adherent macrophages from granuloma induced by $\mathrm{KMnO}$ : inhibiton by NDGA. Pharmacol Res 2007; accepted manuscript.

18. KwaK HB, Lee SW, Jin HM, Ha H, Lee SH, Takeshita S et al.. Monokine induced by interferon-gamma is induced by receptor activator of nuclear factor-B ligand and involved in osteoclast adhesion and migration. Blood 2005;105:2963-2969.

19. Costa GC, Silva RM, Franco-Penteado CF, Antunes E, Ferreira HHA. Interaction between eotaxin and interleukin-5 in the chemotaxis of primed and non-primed human eosinophils. Eur J Pharmacol 2007;566:200-205.

20. Mir A, Minguez M, Tatay J, Pascual I, Pena A, Sanchiz V et al.. Elevated serum eotaxin levels in patients with inflammatory bowel disease. Am J Gastro 2002;97:1452-1457.

Accepted February 29, 2008 